\section{Epidemiological, Endocrine and Metabolic Features in Turner Syndrome}

\section{ABSTRACT}

Turner syndrome is one of the more common genetic disorders, associated with abnormalities of the $X$ chromosome, and occurring in about 50 per 100,000 liveborn girls. Turner syndrome is usually associated with reduced adult height, gonadal dysgenesis, and thus insufficient circulating levels of female sex steroids, and infertility. A number of other signs and symptoms are seen more frequent with the syndrome. Morbidity and mortality is increased. The average intellectual performance is within the normal range. With respect to epidemiology, cardiology, endocrinology and metabolism a number of recent studies have allowed new insight. Treatment with GH during childhood and adolescence allows a considerable gain in adult height. Puberty has to be induced in most cases, and female sex hormone replacement therapy is given during adult years. The proper dose of HRT has not been established, and, likewise, benefits and/or drawbacks from HRT has not been thoroughly evaluated. Since the risk of cardiovascular and endocrinological disease is clearly elevated, proper care during adulthood is emphasized. In summary, Turner syndrome is a condition associated with a number of disease and conditions which are reviewed in present paper. (Arq Bras Endocrinol Metab 2005;49/1:145-156)

Keywords: Adult height; Androgens; Cardiovascular diseases; Epidemiology; Estrogens; Glucose metabolism; Genes; Growth; Growth hormone; Hypertension; Insulinlike growth factor I; Insulin resistance; Ischemic heart disease; Liver function; Morbidity; Mortality; Puberty; Thyroid function; Turner syndrome

\section{RESUMO}

Dados Epidemiológicos, Endócrinos e Metabólicos na Síndrome de Tumer. A síndrome de Turner, decorrente de anomalias dos cromossomos sexuais, é uma das doenças genéticas mais comuns, ocorrendo em cerca de 50:100.000 recémnascidas. A síndrome de Tumer está geralmente associada à baixa estaura, disgenesia gonadal e, portanto, níveis insuficientes de esteróides sexuais femininos, e esterilidade. Vários outros sinais e sintomas são observados mais freqüentemente em portadoras dessa síndrome. Há aumento da morbidade e da mortalidade. A performance intelectual costuma estar dentro da normalidade. Estudos recentes têm trazido novas informações quanto a seus aspectos epidemiológicos, cardiológicos, endócrinos e metabólicos. O tratamento com hGH na infância e na adolescência permite um ganho considerável na estałura final. A puberdade precisa ser induzida na maioria dos casos, e a terapia de reposição de hormônios sexuais femininos (TRH) persiste durante toda a vida adulta. As doses adequadas para TRH ainda não estão bem estabelecidas; do mesmo modo, seus benefícios e/ou desvantagens ainda não foram cuidadosamente avaliados. Uma vez que o risco de doenças cardiovasculares e endócrinas é claramente elevado, o cuidado adequado na vida adulta é enfatizado. Em síntese, a síndrome de Turner é uma afecção associada a diversas anomalias congênitas e adquiridas que são revisadas neste artigo. (Arq Bras Endocrinol Metab 2005;49/1:145-156)

Descritores: Altura final; Andrógenos; Doenças cardiovasculares; Epidemiologia; Estrógenos; Metabolismo da glicose; Genes; Crescimento; Hormônio de cresci mento; Hipertensão; IGF 1; Resistência insulínica; Doença cardíaca isquêmica; Função hepática; Morbidade; Mortalidade; Puberdade; Função tireoideana; Síndrome de Turner

\section{atualização}

Claus Højbjerg Gravbolt
Medical Department, Endocrinology and Diabetes and Medical Research Laboratories, Aarhus University Hospital, Aarhus, Denmark.
Recebido em 03/10/04 Aceito em 04/11/04 
$\mathrm{T}$ URNER SYNDROME (TS) OCCURS in about 50 per 100,000 girls, and, as such, is one of the most frequent chromosomal aberrations in females. The original description focused on infantilism, cubitus valgus and congenital webbing of the neck (1). Later, a number of additional conditions, characteristics, and abnormalities have been described. Turner syndrome has a genetic background, with characteristics involving numerous specialities such as embryology, pediatrics, endocrinology, cardiology, otorhinonology, ophthalmology, and epidemiology.

In this review focus is on aspects of medical management during adulthood with reference to recent genetic discoveries.

\section{EPIDEMIOLOGY}

The designation "Turner syndrome" is a clinical characterization, and no firm guidelines for the diagnosis exist (2), but most agree that the cardinal stigmata include growth retardation with reduced adult height with or without additional phenotypical features, and except in rare cases, also gonadal insufficiency, and infertility. The phenotype must be accompanied by a karyotype with complete or partial absence of one sex chromosome, and in addition, mosaicism with two or more cell-lines may be present.

The genetic background for the Turner syndrome phenotype is highly variable, but includes anomalies of the sex chromosomes (the $\mathrm{X}$ and/or $\mathrm{Y}$ chromosomes). The prototypical karyotype of a textbook female with Turner syndrome is 45 , $\mathrm{X}$; i.e. one $\mathrm{X}$ or one Y chromosome is missing. Statistically it can be estimated that approximately two-thirds of all Turner patients with the 45 , X karyotype should have had the 46 ,XX complement, and one-third the 46,XY complement. Today it is established, however, that most women with Turner syndrome are not carrying the "typical" karyotype of $45, \mathrm{X}$, but rather several different variants all causing the clinical signs of Turner syndrome. The most frequent occurring karyotypes are $45, \mathrm{X}$, karyotypes with an isochromosome of $\mathrm{X}$ (i $(\mathrm{Xq})$ or $\mathrm{i}(\mathrm{Xp})$ ), the mosaic karyotype of $45, \mathrm{X} / 46, \mathrm{XX}$, and karyotypes containing an entire $\mathrm{Y}$ chromosome or parts thereof. It has been claimed that the pure $45, \mathrm{X}$ karyotype does not exist, because such an individual could not survive in utero (3). This claim is supported by meticulous studies examining more than one tissue (i.e. other than lymphocytes) for the presence of mosaicism.

The prenatal prevalence is much higher than the postnatal prevalence (4). This indicates that a high rate of conception of TS fetuses occurs. This is illustrated by a very high prevalence of Turner syndrome karyotypes after chorion villus sampling (performed on average in week 11) of 392 TS fetuses per 100,000 female fetuses compared with a prevalence after amniocentesis (week 16) of 176 per 100,000 (4).

The prevalence of TS is based on a number of cytogenetic studies with estimates ranging from 25210 per 100,000 females (5), and a hypothetical proportion of about 50 per 100,000 girls in Caucasian populations may be agreed upon. Currently, however, the diagnosis of TS is made more infrequent than would be expected from the original cytogenetic surveys $(4,6)$, and a considerable delay in diagnosing girls and adolescents with the syndrome is obvious. In a North American study of 81 females with TS the average diagnostic delay was 7.5 years during childhood and adolescence (6). Interestingly, the key to diagnosis was lymphedema in $97 \%$ during infancy, and short stature in $82 \%$ during childhood and adolescence. Due to the nature of the study (only children) there was no information regarding the key to diagnosis in adults. The study also documented that the vast majority of patients had several stigmata at the time of diagnosis, which would have been expected to facilitate an earlier diagnosis. Thus, the delay in diagnosis could not simply be explained by lack of manifestations of TS in this population. In addition to delay in diagnosis of the syndrome during childhood and adolescence, it must be emphasized that TS is also diagnosed in adults. When studying the entire population of females with TS in Denmark, the median age at diagnosis was 15 years, with a range of 0-86 years (unpublished observations, Gravholt et al.).

Morbidity is increased in Turner syndrome. In a study of all diagnosed females with Turner syndrome and the background population of women in Denmark, we compared incidence rates of diseases suspected to occur with increased frequency (7). The relative risk ( $R R$ ) of an endocrine diagnosis in Turner syndrome patients is increased to 4.9 , being accounted for by an increased risk of hypothyroidism (RR 5.8), thyroiditis (RR 16.6), type 1 diabetes (RR 11.6), and type 2 diabetes (RR 4.4). Likewise, the risk of ischemic heart disease and arteriosclerosis (2.1), hypertension (2.9), and vascular disease of the brain ( RR 2.7), was increased. The risk of other conditions like cirrhosis of the liver (RR 5.7), osteoporosis (RR 10.1), and fractures (RR 2.2) was also increased, as were the risks for congenital malformations of the heart, of the urinary system, of the face, ears, and neck. The relative risk for 
all cancers was 1.35 , with only the risk of colonic and rectal cancers being significantly elevated (RR 4.94). Two studies in Denmark using two different and independent registries, namely the Cancer Registry and the Danish National Registry of Patients, found overall risk of cancer to be comparable to the background population $(7,8)$. Only the risk of cancer of the colon was uniformly found to be increased, possibly due to estrogen deficiency.

Mortality is also increased in Turner syndrome. In a British cohort study the relative risk of death was increased to 4.2 (9), with increases due to diseases in the nervous, digestive, cardiovascular, respiratory and genitourinary systems.

The current knowledge of genetics in Turner syndrome does not explain a significant proportion of the phenotypical characteristics of the syndrome. The diagnosis "Turner syndrome" is easy in typical cases, but often difficult, leading to a quite remarkable delay in diagnosis, as well as non-diagnosis. It is also clear that a number of females with Turner syndrome are never diagnosed. Morbidity and mortality is increased, but the etiology of the abnormalities that leads to this rather substantial increase is not clear.

\section{THE PITUITARY OVARIAN AXIS}

Forty years ago ovaries from fetuses with TS with the 45 , X complement were shown to have a normal germ cell count until week 18 of gestation, after which they seemed to undergo accelerated degeneration (10-11). The gonadal insufficiency is associated with high levels of follicle-stimulating hormone $(\mathrm{FSH})$ and luteinizing hormone ( $\mathrm{LH})$ in early childhood (2-5 years) and after the time of normal onset of puberty (11 years), while during the neonatal period and late childhood the level of FSH and $\mathrm{LH}$ is comparable to those in healthy girls (12). In adulthood, as in other conditions of hypergonadotropic hypogonadism, the level of FSH and $\mathrm{LH}$ is increased to menopausal levels. The view that apoptosis of germ cells in TS is almost complete in the first years of life has recently been challenged by Hreinsson et al., who obtained ovarian biopsies from nine females with Turner syndrome (12-19 years; 4 had pure $45, \mathrm{X})$, and found 1.5-128 follicles per $\mathrm{mm}^{3}$ of the ovarian cortical tissue (13). The authors concluded that cryopreservation for later treatment of infertility might be an option in Turner syndrome. The data also may explain why $30 \%$ or more of females with Turner syndrome show signs of puberty (14), suggesting residual ovarian sex hormone production.
Thus, a thorough evaluation of reproductive capacity is relevant in pubertal females and young adolescents with Turner syndrome. However, another recent study found massive apoptosis of the oocytes of 1520 week TS fetuses (50-70\% of cells, in comparison with $3-7 \%$ of oocytes in normal fetuses) (15), while Reynaud et al. recently examined 10 aborted fetuses with $45, \mathrm{X}$, and found follicle formation and growth severely reduced (16). These latter studies support early studies of increased and rapid apoptosis taking place already in utero.

The average age of menarche in girls varies, by country, by social environment, and by ethnicity. For many years most authors advocated postponing the age of inducing puberty as long as possible in order to achieve an optimal growth response to GH treatment. However, the most ideal timing of endocrine therapy allows induction of puberty in conjunction with the peers of the patient to avoid social problems at school because of delayed physical and psychological development. This would probably also allow optimal bone mineralization to take place. In most normal girls puberty starts around the age of 12 years. However, since up to $30 \%$ of girls with TS will undergo some spontaneous pubertal development and $2-5 \%$ will have spontaneous menses and may have the potential to achieve pregnancy without medical intervention, signs of puberty should be looked for before starting estrogen therapy. When FSH and LH are clearly elevated, and clinical signs of puberty are missing, pubertal induction should be started. It can be postponed for a while, if the individual patient does not suffer from psychological distress because of lack of signs of puberty, when comparing herself to peers. Pubertal development may be delayed if it occurs at all, and, in most cases, is followed by progressive premature ovarian failure.

In order to induce pubertal development, the dosing and timing of estrogen therapy should probably aim at mimicking normal pubertal development, taking into account the individual's desire to begin puberty. Doses should be individualized starting with very low doses of estrogen as monotherapy, which may be monitored in terms of the development of secondary sex characteristics, serum LH and FSH, bone maturation or uterine volume. A gestagen is added when breakthrough bleeding occurs. Estrogen therapy should be coordinated with the use of GH. This should be individualized for each patient, thus optimizing both growth and pubertal development. When growth is a priority, delaying estrogen therapy may be an option to avoid compromising adult height. A 
recent growth hormone trial have documented that a physiological timing of estrogen therapy does not compromise adult height, when GH therapy is started early and dose is increased stepwise (17), while other studies pointed towards postponing estrogen treatment as much as possible. Proper estrogen replacement during puberty may also have positive effects on motor speed, verbal and non-verbal memory and processing $(18,19)$, although proper HRT during adulthood does not seem to correct some of the neuro-cognitive deficits found in Turner syndrome (deficits in visual-spatial abilities, visual-perceptual abilities, motor function, nonverbal memory, executive function, and attention abilities) (20). However, it is not known whether these deficits are sensitive to the dosage of estrogen.

Since most women with Turner syndrome have ovarian dysgenesis, and thus are infertile, this aspect has also to be dealt with. Adult women have rated infertility as their most prominent problem of the syndrome, and most recent studies have shown promising results with oocyte donation, which is an option in many countries. In preparing for the uterus for implantation (uterine size and endometrial thickness) prolonged treatment with high doses of estradiol may be needed (4-6-(8)mg of 17-estradiol) (21). In the future ovarian implantation after cryopreservation may be an option.

With the current state of knowledge puberty should be induced at an appropriate age in comparison with peers. Estradiol should preferably be used in slowly increasing doses until bleeding occurs, when a gestagen should be added and cyclical treatment commenced. HRT should be continued until the age of natural menopause. Only regimens with continuous estrogen exposure should be used, since TS women become absolute estrogen deplete if regimens with a "pill-free week" is used. Bone status and secondary sex characteristics should be monitored.

\section{CARBOHYDRATE METABOLISM AND PHYSICAL FITNESS}

In adolescents and adults a large proportion of TS patients exhibits impaired glucose tolerance or overt type 2 diabetes during an oral glucose tolerance test $(22,23)$. In a recent cross-sectional study of 71 adult TS, fasting levels of glucose and insulin were also comparable to those of controls, leading the authors to conclude that metabolic risk factors (e.g. elevated fasting glucose) were not a concern in TS (24), while others have found insufficient insulin secretion $(23,25)$, pointing towards a deficient $\beta$-cell function.
Type 2 diabetes is frequent (7), and thus, a state of normal fasting glucose and insulin levels, but compromised glucose metabolism during stimulation seems to be present, including elevated 2-hour glucose, and thus presumably also postprandial hyperglycemia.

Most females with TS are treated with hormonal replacement therapy (HRT) after induction of puberty, and this treatment has a moderate influence on carbohydrate metabolism (23). As regards cardiovascular risk factors, 3 major studies have recently been published and presented compelling data relevant to a postmenopausal population, but probably not easily applicable to a younger Turner syndrome population. In healthy postmenopausal women without prior cardiovascular disease the results from the recent Women's Health Initiative randomized trial show that HRT should not be initiated for primary intervention against cardiovascular disease (26). In postmenopausal women with a previous cardiovascular event (secondary intervention), HRT has proved to have no effect on cardiovascular mortality and morbidity (but also to have no detrimental effect) (27); and HRT has also been unsuccessful in postmenopausal women with a previous stroke, albeit not deleterious as secondary intervention (28).

Available data indicates that a large proportion of women with Turner syndrome have an abnormal glucose tolerance and inappropriate high levels of circulating insulin without and during replacement with sex hormones, which could indicate a deranged $\beta$-cell function. In animal models, glucose stimulated insulin release is reduced after ovariectomy and restored by replacement with sex hormones $(29,30)$. Thus, during longer term treatment with sex hormones an improvement in the indices of carbohydrate metabolism may take place; perhaps partly through the expedient effects of sex hormone replacement on physical fitness, body composition, and blood pressure.

Physical fitness (determined by sub-maximal $\mathrm{VO}_{2 \max }$ testing on a bicycle) of TS patients has been found to be diminished by $25 \%$ compared to control subjects (23), also when differences in body composition are taken into consideration, and in this respect they are comparable to healthy relatives to patients with type 2 diabetes, along with reduced insulin sensitivity. A progressive decline in muscle force is normally seen in postmenopausal women however, this decline can be reduced by sex hormone replacement therapy (31). In a randomized trial of HRT +/- exercise and a control group (without exercise) it was shown that HRT with or without exercise was associated with increases in muscle performance, muscle mass, and 
muscle composition (32). The beneficial effect of HRT on muscle was greater when combined with exercise. In Turner syndrome patients, as well as in postmenopausal women, female sex hormones alone or perhaps via an increase in endogenous GH secretion seem pivotal in preventing a deterioration in both fatfree mass and maximal oxygen uptake (33).

Although available evidence documents a number of defects known to lead toward overt type 2 diabetes, long-term studies are needed to examine possible positive effects of HRT (preferably with genuine 17-estradiol and a gestagen) on the increased prevalence of abnormal glucose tolerance and type 2 diabetes. In addition observational studies are needed to study the natural history of the development of type 2 diabetes in Turner syndrome. Treatment with GH induces insulin resistance in TS, as in other conditions, which subsides when treatment is discontinued. HRT induces small changes in glucose homeostasis, and it remains to be seen whether there are any long-term effects on the development of type 2 diabetes. Present recommendations are to continue proper HRT until the age of natural menopause ( $50-55$ years).

\section{ANTHROPOMETRY AND BODY COMPOSITION}

The adult height of Turner patients is approximately $20 \mathrm{~cm}$ below that of the average female population. There is no relation between karyotype and height or any other anthropometrical measurements in most studies, although a few authors have found certain karyotypes to be associated with increased adult height. The anthropometrical composition of women with Turner syndrome is very distinct; Turner females are primarily growth retarded via the longitudinal axis, while the horizontal measurements are comparable to those of control females (33-35). This means that while height, sitting height, and arm-span are reduced by approximately 3-4 SD compared with a reference population, hands and feet are reduced in size to a lesser extent, while head circumference, biacromial and biiliacal diameter are comparable to those of healthy women (figure 1) (36). BMI, W/H, and fat mass (FM) have been found to be higher in adult Turner patients compared with age matched controls, and FFM is lower, implying a higher incidence of adiposity . In addition, we found distinct differences in regional body composition in young TS girls (9-15 years) in comparison with age- and BMI-matched controls. Total FM was increased in TS. This was accoun- ted for by an increased FM in the arms and trunk. Likewise, FFM was decreased in Turner girls, although not reaching statistical significance $(\mathrm{p}=0.09)$. Especially FFM in the legs was decreased (significantly), while FFM in other regions was comparable to that of controls. Overall, bone mineral content (BMC) was diminished, being accounted for by reductions in BMC both in the legs and in the arms (37). In other words, Turner syndrome is a syndrome of disproportionate anthropometry and body composition.

The menopause in healthy women is associated with a change in body composition towards a more android fat distribution and an increase in BMI; a situation which can be postponed by sex steroid replacement. In adult Turner patients a rise in FFM is recorded during sex steroid treatment without any change in BMI or $\mathrm{W} / \mathrm{H}$ ratio. Turner women are characterized not only by increased amounts of body fat, but also by a more android body composition, and treatment with sex hormones slightly improves these abnormalities (33). There are no studies of the effect of discontinuing HRT. This remains interesting in light of the recent studies of HRT in postmenopausal women.

Both anthopometry and body composition is abnormal in Turner syndrome. GH and HRT exert seemingly positive effects on body composition in Turner syndrome, and discontinuation of both GH and HRT are associated with detrimental effects. Long term changes in body composition during both GH treatment and HRT have not been studied. Further, the dosage of HRT and thus a possible impact of body composition have not been studied.

\section{BONE MINERALIZATION}

It is evident that girls, and younger and middle-aged

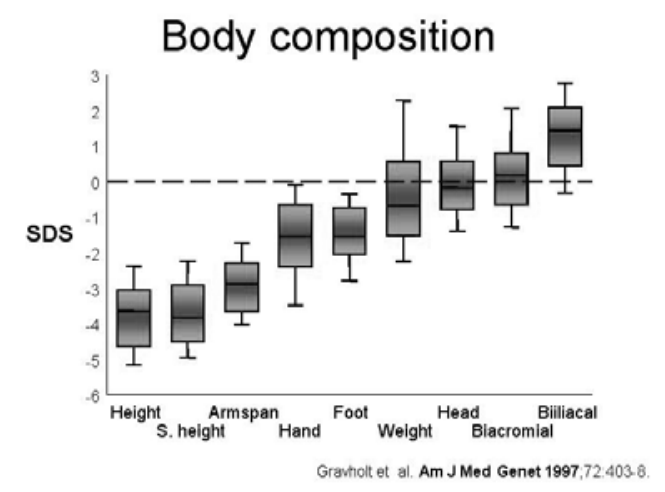

Figure 1. Anthropometric parameters expressed in SDS . 
women with Turner syndrome have low areal bone density, as documented in numerous studies $(38,39)$. There are, however, inherent problems in all these studies - namely the fact that TS subjects are small, and size is a major factor influencing areal BMD (and bone mineral content, BMC) measurements as determined by DEXA (dual energy X-ray absorptiometry), because of the two-dimensional nature of DEXA scanning. Since reduced height is the almost universal finding in TS, addressing this issue is pivotal. Therefore, it is not possible to study BMD with the use of dual densitometry $\mathrm{x}$-ray scans (DEXA) without acknowledging the influence of size. A recent study of adolescents calculated volumetric BMD of the spine and found values that were comparable to those of a reference population (40). In an adult population of 60 TS patients, we found slight, but significant reductions in volumetric BMD (vBMD) in the spine, while vBMD at the hip was actually greater in TS compared with an age-matched control group (4l). However, areal BMD in the arm was severely reduced, pointing to a specific effect of the SHOX gene at this anatomic location, keeping in mind that the SHOX gene is specifically expressed here during embryonal development.

A few studies have looked at fracture frequency. A register-based study has suggested that osteoporosis (RR: 10.1), and fractures (RR: 2.2) are frequent diagnoses in a Turner population (7). The relative risk of fracture was increased for every location investigated (figure 2), but did not reach statistical significance for all locations, a result that could be due to few fractures at specific sites, because of a too small study population. This indicates that the decreased BMD seen in other studies leads to clinical consequences. The risk of fracture was increased already in childhood. In order to further study the number of and site of fracture, we conducted a questionnaire survey of all registered girls and women with Turner syndrome in Denmark. The fracture risk was found to be significantly increased by $25 \%$ in females with TS (42). This is less than found $100 \%$ previously increase (7). However, it fits well with BMD measurements from clinical studies. Using our own previously published BMD values (41), we calculated the expected fracture risk from the data of Marshall et al., and found a relative fracture risk of 1.39 and 1.42 at the spine and hip in TS (43). Furthermore, the increased risk was largely restricted to forearm fractures. In addition, the age at which a fracture occurred was significantly reduced.

Sex hormone replacement therapy is considered crucial to avoid a rapid decrease in BMC. Treatment

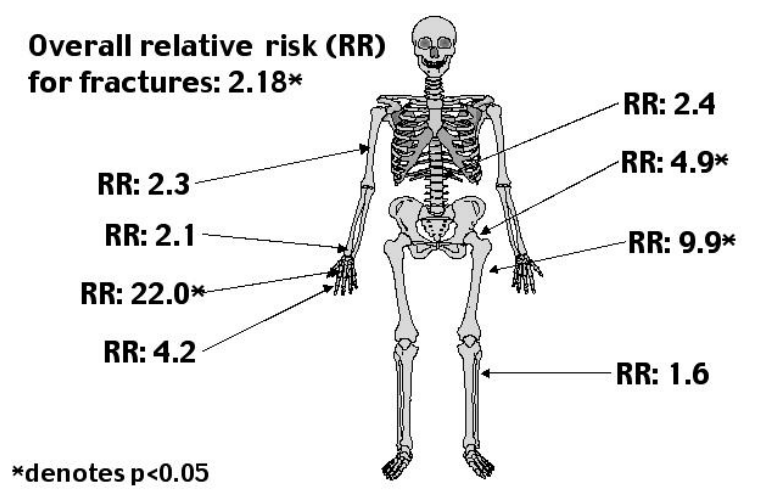

Gravholt et al. J Clin Epidemiol 1998; 51:147-58.

Figure 2. Site-specific risk of fractures expressed as relative risks.

* denotes statistical significance $(p<0.05)$.

with estrogens is needed to induce maximal peak bone mass in adolescents and young adults. This is supported by four longitudinal studies of estrogen deficient as well as estrogen non-deficient adolescents with TS. In these studies patients with spontaneous menstruations had normal BMD, while patients without menstruations had reduced BMD $(44,45)$. Further, $\mathrm{GH}$ seems to improve $\mathrm{BMD}(46,47)$, although in these two small studies no untreated control group of girls with Turner syndrome was included, and the patients were followed for up to 2 years only. In a recent 7 -year study with GH treatment given at 3 different doses, where bone mineral density was studied by phalangeal radiographic absorptiometry, volumetric bone density was found to be normal or increased in a dose-dependent manner (48). However, estrogen was added after 4 years of previous $\mathrm{GH}$ treatment, and it is difficult to ascertain the individual effects of GH and estrogen in this study. Most (83\%) adult Danish women with TS do receive HRT (42).

Recently, a 3-year longitudinal study of 21 women with TS (age 20-40) with iliac crest biopsies before, and 3 years after treatment with HRT showed compelling effects of estrogen on bone. The women were treated with estradiol implants (and oral gestagen cyclically) (49). The implants resulted in estradiol levels comparable to levels normally present in premenopausal women, and considerably higher than the levels achieved with the regimens (estradiol $2 \mathrm{mg}$ orally or equivalent transdermal doses, i.e. traditional HRT regimens used for postmenopausal women) used hitherto. Bone biopsies showed an increase in cancellous bone volume, a decrease in activation frequency, but the active formation period was increased. Wall thickness was increased, indicating an increase in bone formed at each individual remodelling unit. In parallel, 
$\mathrm{BMD}$ at the lumbar spine and femoral neck increased with $13 \%$ and $8 \%$, respectively. The data were interpreted as evidence of an anabolic effect on the skeleton of estradiol at these doses in young women with Turner syndrome.

Untreated girls and women with TS have low bone mass, but this seems to be quite easily overcome be adequate (both in timing and dosage) by appropriate $\mathrm{GH}$ and estradiol treatment. No very long term studies (both follow-up and intervention studies) of the effect estradiol have been published. There is a definite need for such studies to determine the ideal treatment regimen during adolescence for achieving 2 goals: 1) attaining maximal peak bone mass and maintaining BMD without compromising adult height, and 2 ) with appropriate timing of pubertal induction to achieve appropriate secondary sex characteristics. Furthermore, the dosage of estrogen during adult life has to be determined. There are indications that the present dosage (i.e. $2 \mathrm{mg}$ of estradiol or equivalent) is insufficient in terms of bone health and also with reference to secondary characteristics. However, it is at present unknown how a higher dose may influence other aspects of adult TS.

\section{THYROID FUNCTION}

Thyroid dysfunction is common in TS. Hypothyroidism is frequent, and thyroid antibody formation even more so, especially in a subgroup with an isochromosome of the long arm of the X chromosome $(\mathrm{i}(\mathrm{Xq}))$, and as many as $30 \%$ or more eventually develop hypothyroidism. Many adult Turner subjects seem to suffer from compensated hypothyroidism, which often progresses into overt hypothyroidism. However, it remains an enigma why so many TS females have thyroid autoimmune disease. The basis for the grossly increased risk of autoimmunity in Turner syndrome (also including celiac disease, and type 1 diabetes is unaccounted for, and a genetic basis seems probable. A recent study shows increased tumor necrosis factor receptor- and CD95-mediated apoptosis in cord blood T-cells (CD4+ and CD8+ cells) (50), and earlier studies found minor deficiencies of humoral and cellular immunity, and it may be that these more or less discrete deficiencies in combination explain the increased risk of autoimmunity.

Thus, hypothyroidism with antibody formation is extremely common in TS and has to be looked for continuously. Treatment consists of levothyroxine, and in some cases liothyronine, in usual doses.

\section{ANDROGEN INSUFFICIENCY}

Since approximately half of the testosterone production in normal females originates from the gonads, one would anticipate Turner syndrome patients are also androgen deficient, which indeed has been reported $(51,52)$. Thus, there may be a rationale for treating the females with Turner syndrome with androgens. No studies have, so far, addressed the issue of androgen replacement in adults. Androgen supplementation could be postulated to have beneficial effects on the excess of sexual problems, which has been described in Turner syndrome. In addition, androgen supplementation would possibly have positive effects on the reduced bone mineral content, manifest osteoporosis and an increased incidence of fractures, as well as the characteristic anthropometry and body composition of Turner syndrome.

\section{HEPATIC FUNCTION}

Women with Turner syndrome have a high frequency of elevated liver parameters. One study found elevated levels of hepatic enzymes in $80 \%$ of middle aged women with Turner syndrome, but could not associate the findings with overt hepatic disease (53). We found the serum levels of alanine aminotransferase, glutamyl transferase, and total alkaline phosphatase to be higher in Turner patients compared with controls. The elevated levels of some hepatic enzymes and proteins are not associated with overt hepatic disease, and it should be emphasized that women with Turner syndrome do not seem to consume more alcohol than other women (23). Still, recent epidemiological evidence suggests that cirrhosis of the liver is more frequent in Turner syndrome (7). In a recent study liver biopsies were performed in 27 women with Turner syndrome, because of persistently elevated liver tests (54). Multiple abnormalities were found, including marked nodular regenerative hyperplasia $(n=6)$, multiple focal nodular hyperplasia $(n=2)$, and cirrhosis $(n=2)$, associated, in some, with obliterative portal venopathy. Other patients showed more moderate changes, including portal fibrosis, inflammatory infiltrates, and non-alcoholic fatty liver disease. One patient underwent liver transplantation. The authors concluded that the main causes of liver abnormalities in Turner syndrome are vascular disorders thought to be congenital in origin, and non-alcoholic fatty liver 
disease, without signs of liver toxicity from concomitant estrogen therapy (54). The study is important, since it is the largest, includes liver biopsies, as well as thorough evaluation of other causes of liver disease, excluding viral, auto-immune and alcoholic causes, and because it apparently excludes estrogen therapy as a player in the liver abnormalities.

Rather unexpectedly we found a significant decrease in the level of liver enzymes after treatment with sex hormones, irrespective of route of administration (oral or transdermal 17-estradiol) (23). These results have recently been corroborated by an Israeli study of young adults treated with either ethinyl estradiol (30mcg) or conjugated estrogens $(0.625 \mathrm{mg})$, both combined with an oral gestagen, in whom liver enzymes were lowered by treatment in comparison with no treatment $(55)$. The enzymes were suppressed more with ethinyl estradiol than conjugated estrogens. We hypothesize that sex hormones may have important protective functions in maintaining normal hepatic function, not only in Turner syndrome, but possibly also in healthy women.

\section{THE HEART IN TURNER SYNDROME}

Much of the increased morbidity and mortality noted in Turner syndrome is attributable to different heart conditions. Some of these are congenital and others are acquired.

Congenital malformations related to the heart and great vessels are very frequent in Turner syndrome, especially with the 45,X karyotype (figure 3 ). The prevalence and the nature of cardiovascular malformations have been described in several studies (table 1) (56-60). The malformations normally involve both vessels of the left and the right side of the heart, and show a very characteristic pattern when compared with the general population. In the recent large study by Sybert, it was shown that cardiac malformations are more prevalent among the subgroup of patients with $45, \mathrm{X}(39 \%)$, than among those with karyotypes that include an isochromosome (Xq) (11-12\%) (mosaic or not) (59).

The cause of congenital heart defects in Turner syndrome remains unknown. An increase in aortic root diameter, which is a risk factor for developing aortic dilatation and later rupture, is often seen and probably

Table 1. Data on congenital malformations are complied from 5 studies with apparent unbiased inclusion of patients. Number of affected/total number examined, and percentage are given in the table.

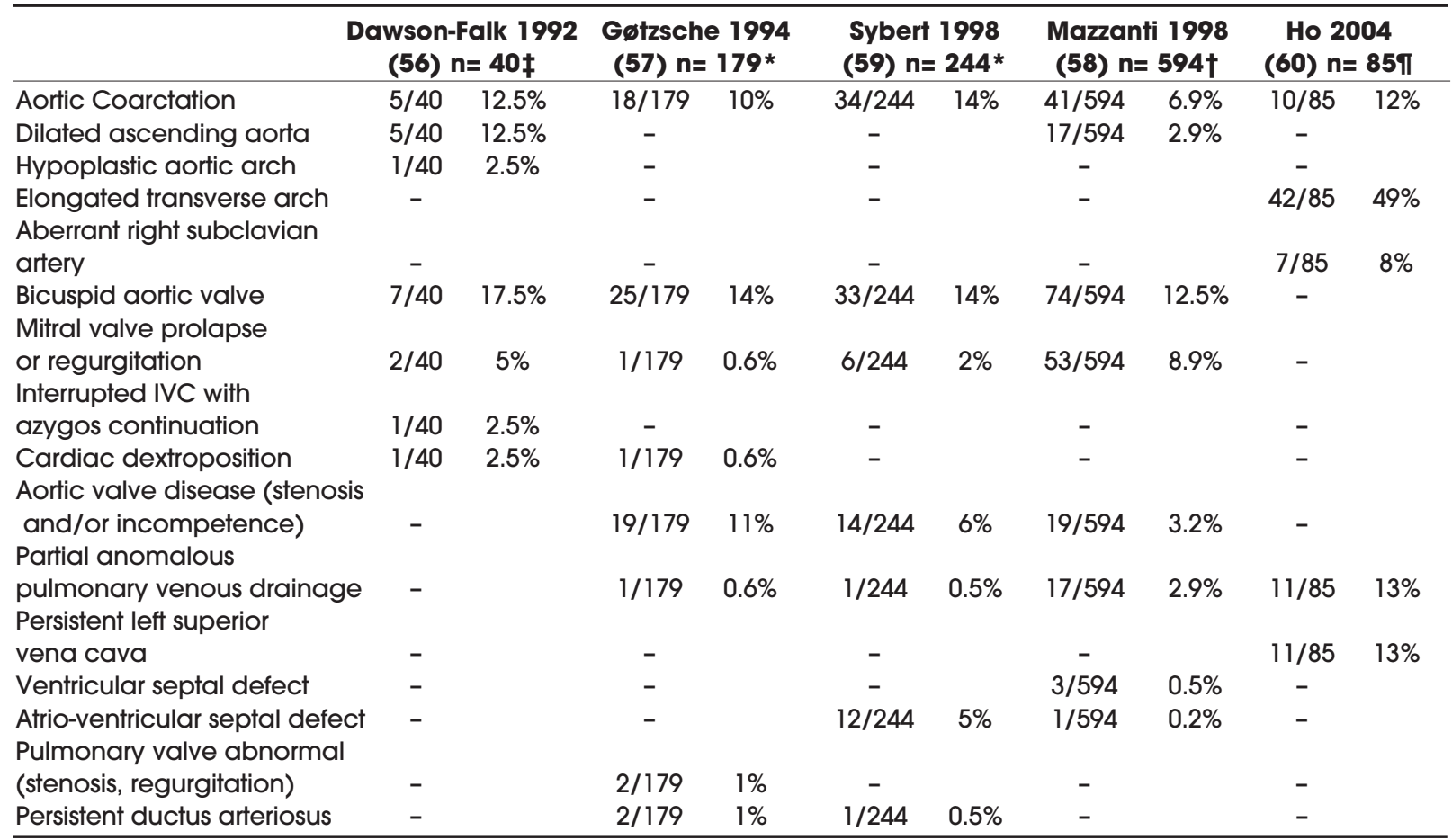

* Patients were only examined with clinical exam and echocardiography. † Patients were examined with clinical exam, ECG, chest X-ray, and transthoracic echocardiography. $\ddagger$ Patients were examined by MRI scan and echocardiography. "-" = not reported or not evaluated. ๆ Patients were examined by gadolinium-enhanced MR angiography. 


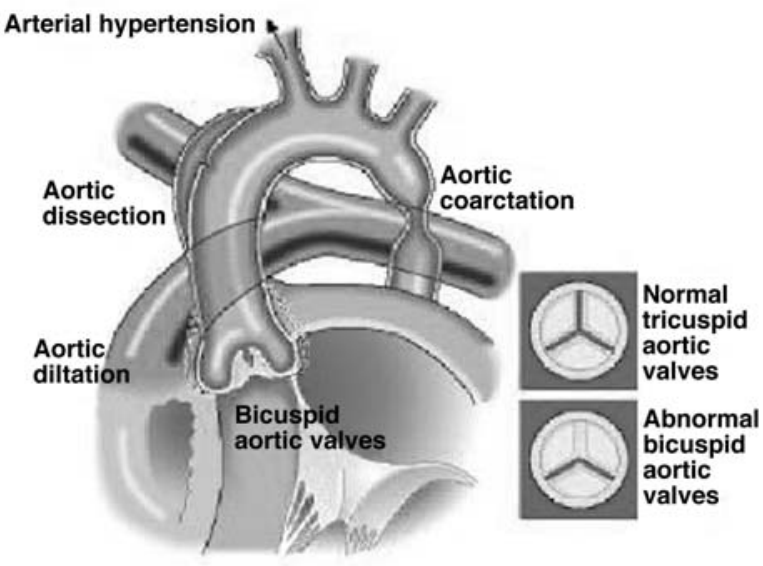

Figure 3. Illustration showing the typical congenital cardiovascular malformations seen in Turner syndrome, i.e. coarctation of the aorta, and bicuspid aortic valves. The figure also illustrates the occurrence of aortic dilatation and dissection. Please note that presence of congenital malformations and/or systemic hypertension is not a prerequisite for the development of dilatation and dissection of the aorta.

depends on blood pressure (61). However, prospective studies are needed in order to study how the risk of aortic dissection can be reduced.

Thirty percent of girls with Turner syndrome are mildly hypertensive on 24-hour ambulatory blood pressure monitoring, and $50 \%$ have an abnormal diurnal blood pressure profile (62).

Women with Turner syndrome have significantly elevated blood pressure compared with an age matched control group, and as many as $50 \%$ have clinical hypertension. Treatment with sex hormones caused a significant reduction in the 24-hour blood pressure (23). Presently there are no longitudinal studies of blood pressure and hypertension in Turner syndrome. There is a definite need for such studies. Furthermore, it is essential to establish the effect of treatment and to determine which drugs to choose as first- and second-line treatment.

More than 60 case reports of aortic dilatation or dissection, some of which were fatal, have been described (reviewed in ref. 59). In most cases, risk factors were present. In the general population risk factors for aortic dissection include systemic hypertension, which is present in up to $90 \%$ of cases, congenital bicuspid or unicommissural aortic valves, and coarctation of the aorta. In addition, pregnancy, trau$\mathrm{ma}$, and iatrogenic-induced trauma are risk factors. Usually, but not always, the abovementioned risk factors (other than Turner syndrome) are known to be present in the reported cases of aortic dissection in
Turner syndrome. Aortic root dilatation, which is a risk factor for later rupture, is often seen and seems to be associated with elevated systolic blood pressure. Undoubtedly Turner syndrome should be included in this list of risk factors for aortic dissection. Presently, no abnormality of the aortic wall has been identified in Turner syndrome. Pregnancy is a rare event in Turner syndrome. Owing to an increasing number of egg donation programs more patients can be expected to go through pregnancy in the future. Due to the pregnancy associated changes blood pressure, cardiac work load, etc., the risk of aortic dissection is likely to be increased. Uneventful cases of pregnancy have been reported, however, fatal and non-fatal cases due to aortic dissection have also been described.

Prospective studies are needed in order to establish the exact risk of aortic dissection, identify patients at an elevated risk, and, if possible, to introduce procedures and/or medicine to lower the risk, both during pregnancy and during normal life.

The chronic estrogen deficiency affecting many adult women with Turner syndrome is likely to be associated with cardiovascular morbidity. Part of the increased cardiovascular morbidity and mortality in Turner syndrome could therefore be explained by non-use of estrogens.

At present, no long-term studies have assessed the impact of HRT on the heart and on the increased mortality seen in Turner syndrome. It might be speculated that HRT would have positive effects on aortic effect on the aortic wall has not been described. Far from all patients receive HRT during adulthood, and many adolescents are introduced to estrogens rather late, in order to achieve the highest adult height. Hypertension is frequent among patients with Turner syndrome (see above), and treatment with female hormone replacement therapy cause a small, but significant reduction in the 24-hour blood pressure.

Presently, there is no consensus concerning a number of issues: 1) the pathophysiology, especially during adulthood, is not described in any great detail, 2) the natural history, due to few long-term follow-up studies, 3) how aggressive should hypertension be treated, and which drugs to choose as first line drug?, 4) especially the concept of aortic dilatation needs to be dealt with in greater detail. What effect does HRT have during the long term, and how does antihypertensive treatment affect the aorta? 5) how dangerous is child bearing in TS? There are no doubt other imminent issues. With our current state of knowledge pertinent clinical guidelines are suggested in the following section.

A cardiovascular risk profile should be deter- 
mined at diagnosis, during adolescence, and in adulthood, and the patient informed about risks and benefits from GH, and HRT. Patients should be seen by a cardiologist and an echocardiography performed, together with clinical examination (table 2). When pubertal induction is taking place, it may be prudent to perform a new cardiovascular assessment, and likewise in adulthood (4). If any congenital cardiac malformation is present, this should be dealt with properly, relevant examinations and tests performed, and the patient should be followed with regular intervals. Endocarditis prophylaxis should be given in case of bicuspid aortic valves, and in case of any surgical procedures having been performed. The potential consequences of $\mathrm{GH}$ on the heart and great vessels should be discussed, as well as consequences of HRT, and perhaps especially the consequences of not taking HRT. Based on the available literature HRT is recommended during adulthood. The unsolved problem of who will eventually develop dilatation of the aorta, and thus at great risk of later aortic dissection, leaves the patient and her physician in a situation where repeat echocardiographies, at present, are the only solution. Currently, it is not known how frequent echocardiog-

Table 2. Clinical practice of patients with Turner syndrome, with respect to the heart and the great vessels.

1. Echocardiography at diagnosis should be performed in all patients. If normal, or near-normal repeat echocardiography should then be performed in adolescence, in adulthood, and probably every 5 years hereafter. A close working relationship with a cardiologist with knowledge of TS is of great value.

2. If congenital cardiac malformations are diagnosed, these should be dealt with appropriately (see text). This includes:

- operation, if deemed clinically necessary;

- regular clinical exams (echocardiography, MRI scan, blood tests, blood pressure, etc.);

- prophylaxis for infectious endocarditis (visits at the dentist, minor surgery, etc.).

3. The potential consequences of $\mathrm{GH}$ treatment should be evaluated.

4. The benefits and drawbacks of HRT should be discussed with the patient at a relevant age. At present HRT is recommended.

5. Evaluation of the aorta, with emphasis on aortic dilatation, and the subsequent risk of aortic dissection.

6. Cardiac monitoring prior to $\mathrm{ART}^{\star}$ or spontaneous pregnancy, and during pregnancy.

7. Risk of ischemic heart disease.

8. Blood pressure monitoring at every visit at the physician.

* ART: assisted reproductive therapy. raphy (and/or MRI) should be performed. At every visit blood pressure should be monitored. During childhood normative blood pressure data corrected for height and age should be used, while usual guidelines apply in adulthood. It is recommended to take special cautionary steps before and during pregnancy, whether spontaneous or assisted, with cardiac monitoring (heart auscultation, blood pressure, echocardiography, and/or MRI (only on vital indication during pregnancy), etc.) at regular intervals.

\section{REFERENCES}

1. Turner HH. A syndrome of infantilism, congenital webbed neck, and cubitus valgus. Endocrinology 1938;23:566-74.

2. Saenger $P$, Wikland KA, Conway GS, Davenport M, Gravholt $\mathrm{CH}$, Hintz R, et al. Recommendations for the diagnosis and management of Turner syndrome. J Clin Endocrinol Metab 2001;86:3061-9.

3. Held KR, Kerber S, Kaminsky E, Singh S, Goetz P, Seemanova $E$, et al. Mosaicism in 45,X Turner syndrome: does survival in early pregnancy depend on the presence of two sex chromosomes? Hum Genet 1992;88:288-94.

4. Gravholt $\mathrm{CH}$, Juul S, Naeraa RW, Hansen J. Prenatal and postnatal prevalence of Turner's syndrome: a registry study. Br Med J 1996;312:16-21.

5. Nielsen J, Wohlert M. Chromosome abnormalities found among 34,910 newborn children: results from a 13-year incidence study in Aarhus, Denmark. Hum Genet $1991 ; 87: 81-3$.

6. Savendahl L, Davenport ML. Delayed diagnoses of Turner's syndrome: proposed guidelines for change. J Pediatr 2000;137:455-9.

7. Gravholt $\mathrm{CH}$, Juul S, Naeraa RW, Hansen J. Morbidity in Turner syndrome. J Clin Epidemiol 1998;51:147-58.

8. Hasle H, Olsen JH, Nielsen J, Hansen J, Friedrich U, Tommerup N. Occurrence of cancer in women with Turner syndrome. Br J Cancer 1996;73:1 156-9.

9. Swerdlow AJ, Hermon C, Jacobs PA, Alberman E, Beral $\mathrm{V}$, Daker $\mathrm{M}$, et al. Mortality and cancer incidence in persons with numerical sex chromosome abnormalities: a cohort study. Ann Hum Genet 2001;65:177-88.

10. Carr DH, Haggar RA, Hart AG. Germ cells in the ovaries of XO female infants. Am J Clin Pathol 1968;49:521-6.

11. Singh RP, Carr DH. The anatomy and histology of XO human embryos and fetuses. Anat Rec 1966;155:36983.

12. Conte FA, Grumbach MM, Kaplan SL. A diphasic pattern of gonadotropin secretion in patients with the syndrome of gonadal dysgenesis. J Clin Endocrinol 
Metab 1975;40:670-74.

13. Hreinsson JG, Otala M, Fridstrom M, Borgstrom B, Rasmussen $\mathrm{C}$, Lundqvist $\mathrm{M}$, et al. Follicles are found in the ovaries of adolescent girls with Turner's syndrome. J Clin Endocrinol Metab 2002;87:3618-23.

14. Pasquino AM, Passeri F, Pucarelli I, Segni M, Municchi G. Spontaneous pubertal development in Turner's syndrome. Italian Study Group for Turner's Syndrome. J Clin Endocrinol Metab 1997;82:1810-3.

15. Modi DN, Sane S, Bhartiya D. Accelerated germ cell apoptosis in sex chromosome aneuploid fetal human gonads. Mol Hum Reprod 2003;9:219-25.

16. Reynaud K, Cortvrindt R, Verlinde F, De Schepper J, Bourgain C, Smitz J. Number of ovarian follicles in human fetuses with the 45,X karyotype. Fertil Steril 2004;81:1112-9.

17. Van Pareren YK, de Muinck Keizer-Schrama SM, Stijnen $\mathrm{T}$, Sas TC, Jansen M, Otten BJ, et al. Final height in girls with Turner syndrome after long-term growth hormone treatment in three dosages and low dose estrogens. J Clin Endocrinol Metab 2003;88:1119-25.

18. Ross JL, Roeltgen D, Feuillan P, Kushner H, Cutler-GB J. Effects of estrogen on nonverbal processing speed and motor function in girls with Turner's syndrome. J Clin Endocrinol Metab 1998;83:3198-204.

19. Ross JL, Roeltgen D, Feuillan P, Kushner H, Cutler GB, Jr. Use of estrogen in young girls with Turner syndrome: effects on memory. Neurology 2000;54:164-70.

20. Ross JL, Stefanatos GA, Kushner H, Zinn A, Bondy C, Roeltgen D. Persistent cognitive deficits in adult women with Turner syndrome. Neurology 2002;58:218-25.

21. Foudila T, Soderstrom AV, Hovatta O. Turner's syndrome and pregnancies after oocyte donation. Hum Reprod 1999; 14:532-5

22. Holl RW, Kunze D, Etzrodt H, Teller W, Heinze E. Turner syndrome: final height, glucose tolerance, bone density and psychosocial status in 25 adult patients. Eur J Pediatr 1994;153:11-6.

23. Gravholt CH, Naeraa RW, Nyholm B, Gerdes U, Christiansen E, Schmitz O, et al. Glucose metabolism, lipid metabolism, and cardiovascular risk factors in adult Turner syndrome: the impact of sex hormone replacement. Diabetes Care 1998;21:1062-70.

24. Landin-Wilhelmsen K, Bryman I, Wilhelmsen L. Cardiac malformations and hypertension, but not metabolic risk factors, are common in turner syndrome. J Clin Endocrinol Metab 2001;86:4166-70.

25. Bakalov VK, Cooley MM, Quon MJ, Luo ML, Yanovski JA, Nelson LM, et al. Impaired insulin secretion in the Turner metabolic syndrome. J Clin Endocrinol Metab 2004;89:3516-20.

26. Rossouw JE, Anderson GL, Prentice RL, LaCroix AZ, Kooperberg C, Stefanick ML, et al. Risks and benefits of estrogen plus progestin in healthy postmenopausal women: principal results From the Women's Health Initiative randomized controlled trial. JAMA 2002;288:321-33.

27. Hulley S, Grady D, Bush T, Furberg C, Herrington D, Riggs
B, et al. Randomized trial of estrogen plus progestin for secondary prevention of coronary heart disease in postmenopausal women. Heart and Estrogen/progestin Replacement Study (HERS) Research Group. JAMA 1998;280:605-13.

28. Viscoli CM, Brass LM, Kernan WN, Sarrel PM, Suissa S, Horwitz RI. A clinical trial of estrogen-replacement therapy after ischemic stroke. N Engl J Med 2001;345:12439.

29. Bailey CJ, Ahmed Sorour H. Role of ovarian hormones in the long-term control of glucose homeostasis. Effects of insulin secretion. Diabetologia 1980;19:475-81.

30. Kumagai S, Holmang A, Bjorntorp P. The effects of oestrogen and progesterone on insulin sensitivity in female rats. Acta Physiol Scand 1993;149:91-7.

31. Phillips SK, Rook KM, Siddle NC, Bruce SA, Woledge RC. Muscle weakness in women occurs at an earlier age than in men, but strength is preserved by hormone replacement therapy. Clin Sci Colch 1993;84:95-8.

32. Sipila S, Taaffe DR, Cheng S, Puolakka J, Toivanen J, Suominen $\mathrm{H}$. Effects of hormone replacement therapy and high-impact physical exercise on skeletal muscle in post-menopausal women: a randomized placebocontrolled study. Clin Sci (Lond) 2001;101:147-57.

33. Gravholt $\mathrm{CH}$, Naeraa RW, Fisker S, Christiansen JS. Body composition and physical fitness are major determinants of the growth hormone-IGF axis aberrations in adult Turner syndrome, with important modulations by treatment with 17-beta-estradiol. J Clin Endocrinol Metab 1997;82:2570-7.

34. Park E. Body shape in Turner's syndrome. Hum Biol 1977;49:215-23.

35. Varrela J, Vinkka H, Alvesalo L. The phenotype of $45, X$ females: an anthropometric quantification. Ann Hum Biol 1984; 1 1:53-66.

36. Gravholt CH, Naeraa RW. Reference values for body proportions and body composition in adult women with Turner's syndrome. Am J Med Genet 1997;72:403-8.

37. Gravholt CH, Naeraa RW, Brixen K, Kastrup KW, Mosekilde L, Jørgensen JO, et al. Short term growth hormone treatment in girls with Turner syndrome decreases fat mass and insulin sensitivity. A randomized double-blind, placebo-controlled cross-over study. Pediatrics 2002; 1 10:889-96.

38. Stepan JJ, Musilova J, Pacovsky V. Bone demineralization, biochemical indices of bone remodeling, and estrogen replacement therapy in adults with Turner's syndrome. J Bone Miner Res 1989;4:193-8.

39. Landin-Wilhelmsen K, Bryman I, Windh M, Wilhelmsen L. Osteoporosis and fractures in Turner syndrome-importance of growth promoting and oestrogen therapy. Clin Endocrinol (Oxf) 1999;51:497-502.

40. Bertelloni S, Cinquanta L, Baroncelli GI, Simi P, Rossi S, Saggese $G$. Volumetric bone mineral density in young women with Turner's syndrome treated with estrogens or estrogens plus growth hormone. Horm Res 2000;53:726. 
41. Gravholt CH, Lauridsen AL, Brixen K, Mosekilde L, Heickendorff L, Christiansen JS. Marked dysproportionality in bone size and mineral, and distinct abnormalities in bone markers and calcitropic hormones in adult Turner syndrome. A cross-sectional study. J Clin Endocrinol Metab 2002;87:2798-808.

42. Gravholt CH, Vestergaard P, Hermann AP, Mosekilde L, Brixen K, Christiansen JS. Increased fracture rates in Turner's syndrome: a nationwide questionnaire survey. Clin Endocrinol (Oxf) 2003;59:89-96.

43. Marshall $D$, Johnell $O$, Wedel $H$. Meta-analysis of how well measures of bone mineral density predict occurrence of osteoporotic fractures. $\mathrm{Br}$ Med J 1996;312:1254-9.

44. Emans SJ, Grace E, Hoffer FA, Gundberg C, Ravnikar V, Woods ER. Estrogen deficiency in adolescents and young adults: impact on bone mineral content and effects of estrogen replacement therapy. Obstet Gynecol 1990;76:585-92.

45. Carrascosa A, Gussinye M, Terradas P, Yeste D, Audi L, Vicens-Calvet E. Spontaneous, but not induced, puberty permits adequate bone mass acquisition in adolescent Turner syndrome patients. J Bone Miner Res 2000; 15:2005-10.

46. Lanes R, Gunczler P, Paoli M, Weisinger JR. Bone mineral density of prepubertal age girls with Turner's syndrome while on growth hormone therapy. Horm Res 1995;44:168-71.

47. Neely EK, Marcus R, Rosenfeld RG, Bachrach LK. Turner syndrome adolescents receiving growth hormone are not osteopenic. J Clin Endocrinol Metab 1993;76:8616.

48. Sas TC, de Muinck Keizer-Schrama SM, Stijnen T, van Teunenbroek A, Van Leeuwen WJ, Asarfi A, et al. Bone mineral density assessed by phalangeal radiographic absorptiometry before and during long-term growth hormone treatment in girls with Turner syndrome participating in a randomized dose-response study. Pediatr Res 2001;50:417-22.

49. Khastgir G, Studd JW, Fox SW, Jones J, AlaghbandZadeh J, Chow JW. A longitudinal study of the effect of subcutaneous estrogen replacement on bone in young women with Turner syndrome. J Bone Miner Res 2003; 18:925-32.

50. Gupta S, Chiplunkar S, Gupta A, Gollapudi S. Increased spontaneous, tumor necrosis factor receptor- and CD95 (Fas)-mediated apoptosis in cord blood T-cell subsets from Turner syndrome. Genes Immunol 2003;4:239-43.

51. Apter D, Lenko HL, Perheentupa J, Soderholm A, Vihko $R$. Subnormal pubertal increases of serum androgens in Turner syndrome. Horm Res 1982; 16:164-73.

52. Gravholt CH, Svenstrup B, Bennett P, Christiansen JS. Low androgen levels in adult Turner syndrome: influence of female sex hormones and growth hormone status. Clin
Endocrinol (Oxf) 1999;50:791-800.

53. Sylven L, Hagenfeldt K, Brondum NK, von Schoultz B. Middle-aged women with Turner syndrome. Medical status, hormonal treatment and social life. Acta Endocrinol 1991;125:359-65.

54. Roulot D, Degott C, Chazouilleres O, Oberti F, Cales P, Carbonell $\mathrm{N}$, et al. Vascular involvement of the liver in Turner syndrome. Hepatology 2004;39:239-47.

55. Guttmann H, Weiner Z, Nikolski E, Ish-Shalom S, ItskovitzEldor J, Aviram M, et al. Choosing an oestrogen replacement therapy in young adult women with Turner syndrome. Clin Endocrinol (Oxf) 2001;54:159-64.

56. Dawson FKL, Wright AM, Bakker B, Pitlick PT, Rosenfeld RG. Cardiovascular evaluation in Turner syndrome: utility of MR imaging. Austr Radiol 1992;36:204-9.

57. Gotzsche CO, Krag Olsen B, Nielsen J, Sorensen KE, Kristensen BO. Prevalence of cardiovascular malformations and association with karyotypes in Turner's syndrome. Arch Dis Child 1994;71:433-6.

58. Mazzanti L, Cacciari E. Congenital heart disease in patients with Turner's syndrome. Italian Study Group for Turner Syndrome (ISGTS). J Pediatr 1998;133:688-92.

59. Sybert VP. Cardiovascular malformations and complications in Turner syndrome. Pediatrics 1998;101:E11.

60. Ho VB, Bakalov VK, Cooley M, Van PL, Hood MN, Burklow TR, et al. Major vascular anomalies in turner syndrome: prevalence and magnetic resonance angiographic features. Circulation 2004;110:1694-700.

61. Elsheikh M, Casadei B, Conway GS, Wass JA. Hypertension is a major risk factor for aortic root dilatation in women with Turner syndrome. Clin Endocrinol (Oxf) 2001;54:69-73.

62. Nathwani NC, Unwin R, Brook CG, Hindmarsh PC. Blood pressure and Turner syndrome. Clin Endocrinol (Oxf) 2000; $52: 363-70$.

63. Elsheikh M, Bird R, Casadei B, Conway GS, Wass JA. The effect of hormone replacement therapy on cardiovascular hemodynamics in women with Turner syndrome. J Clin Endocrinol Metab 2000;85:614-8.

\section{Endereço para correspondência:}

Claus Højbjerg Gravholt

Medical Department - Endocrinology and Diabetes

Århus Kommunehospital

DK-8000 Aarhus C, Denmark

E-mail: ch.gravholt@dadlnet.dk 